\title{
Anomalous Rearrangements of the Immunoglobulin Heavy Chain Genes in Human Leukemias Support the Loop-out Mechanism of Class Switch
}

\author{
Michael Laffan and Lucio Luzzatto \\ Department of Haematology and Medical Research Council/Leukaemia Research Fund Leukaemia Unit, \\ Royal Postgraduate Medical School, London W12 ONN, United Kingdom
}

\begin{abstract}
Discrete rearrangements of immunoglobulin genes are characteristic of lymphoproliferative diseases of $B$ cells and provide direct evidence of their clonal nature. In addition, because leukemic transformation and growth may amplify $B$ cell clones regardless of selection by antigen, analysis of rearranged $\mathrm{Ig}$ genes in leukemic clones may give insight into molecular events taking place during the ontogenesis of normal $B$ cells. We have tested DNA samples from patients with chronic B cell leukemias in search for abnormal rearrangements of the Ig heavy chain gene region. By Southern blot analysis we found an unexpected break in the $\mathrm{JH}-\mathrm{C} \mu$ region in 7 out of 118 cases. Two of these cases were investigated in detail by constructing from each a phage genomic library and isolating the phage clones containing the break points. In both cases the $\mathrm{JH}-\mathrm{C} \mu$ separation was confirmed. Further analysis demonstrated that in both cases the abnormality was an inversion of the Ig heavy chain gene between $\mathrm{C} \mu$ and one of the $\mathrm{C}$ gamma segments. This inversion structure strongly suggests that, as has been demonstrated in murine cell lines and in splenocytes stimulated in vitro, class switching in human B lymphocytes occurs in vivo via a loop-out deletion mechanism. The frequency of abnormal events may be as high as $15 \%$. Our data indicate that a proportion of cases of chronic B cell leukemia arise from a cell which has attempted an Ig class switch. (J. Clin. Invest. 1992.90:2299-2303.) Key words: immunoglobulin • heavy chain • class switch • leukemia
\end{abstract}

\section{Introduction}

Normal B lymphocyte development is characterized by the rearrangement of the genes encoding the light and heavy chains of the Ig molecule, the characteristic product of these cells. Rearrangements altering the germline configuration of these genes are required for their expression. As with any physiological process, errors can occur, particularly if the process is a complex one. Errors in Ig rearrangement are of interest for two principal reasons. Firstly, they have helped in understanding normal rearrangement. Secondly, in some cases rearrangement has brought together Ig genes and cellular protooncogenes in such a manner as to contribute to oncogenesis. The singularity of the Ig rearrangement in each B lymphocyte has provided an

Address reprint requests to Dr. M. A. Laffan, Department of Haematology, Royal Postgraduate Medical School, London W12 ONN, United Kingdom.

Received for publication 4 November 1991 and in revised form 23 March 1992.

J. Clin. Invest.

(C) The American Society for Clinical Investigation, Inc. $0021-9738 / 92 / 12 / 2299 / 05 \quad \$ 2.00$

Volume 90, December 1992, 2299-2303 extremely useful marker to show the clonal origin of malignancies arising in these cells. Moreover, by amplifying such individual rearrangements, lymphoid malignancies provide an ideal material for studying these rearrangements in detail.

Rearrangement abnormalities with a pathogenic role were first detected in the course of investigations of neoplastic cells consistently associated with defined cytogenetic abnormalities, e.g., the $t(8 ; 14)$ in Burkitt's lymphoma and the $t(14 ; 18)$ in follicular lymphoma. On the other hand, it is to be expected that many aberrations will be too small to be seen by such techniques, either because they are intrachromosomal or because they involve the transfer of relatively small portions of DNA (as has been found in Philadelphia negative, bcr positive chronic granulocytic leukemia [1]). Moreover, cytogenetic techniques have been often technically unsuccessful, particularly in chronic lymphocytic leukemia. Attempts to increase the success rate of cytogenetic analysis using mitogens introduces the risk of selecting certain populations of normal or abnormal cells producing unrepresentative results. In contrast, molecular techniques have the advantage of a high degree of sensitivity and do not require the induction of mitosis.

In the light of these observations we decided to search for such abnormalities in human monoclonal B cell populations. We report here that in some cases of chronic lymphocytic leukemia an anomalous $\operatorname{Ig}$ heavy chain $(\mathrm{IgH})^{1}$ rearrangement produces an inversion within this region not hitherto described in human B cells. Our findings support the loop-out model for the class switch and illustrate how expansion of a malignant $B$ cell clone can help to understand molecular events required for functional expression of $\mathrm{Ig}$ genes.

\section{Methods}

DNA was extracted from Lymphoprep (Nycomed Pharma AS, Oslo, Norway) -separated mononuclear cells using a rapid technique. $10 \mu \mathrm{g}$ of DNA was digested to completion using BamHI and run on agarose gels before Southern blotting all as previously described (2). Because the fragments studied were relatively large, $0.7 \%$ agarose gels were run for $48 \mathrm{~h}$ to achieve maximum resolution of fragment sizes. Duplicate gels were run for separate $\mathrm{JH}$ or $\mathrm{C} \mu$ hybridization under identical conditions or separate hybridizations carried out after stripping of the first probe.

To obtain good quality high molecular weight DNA for cloning a cesium banding method was used ( 3 ). A large aliquot ( $150 \mu \mathrm{g}$ ) of DNA was then digested and run on an agarose gel in the same way as for Southern blotting. Using appropriate size markers as a guide, an agarose slice estimated to contain the fragment of interest was cut out and the DNA electroeluted. The vector used for cloning was the lambda phage EMBL 3 digested with BamHI as supplied by Stratagene Inc. ( $\mathrm{La}$ Jolla, CA). Approximately $0.4 \mu \mathrm{g}$ of insert DNA was ligated to $1 \mu \mathrm{g}$ of vector DNA under standard conditions (3). Aliquots of this ligation were then packaged in vitro using sonicated and freeze-thaw lysates

1. Abbreviation used in this paper: $\mathrm{IgH}, \mathrm{Ig}$ heavy chain. 
prepared in our laboratory and then plated on the CS2000 Escherichia coli strain. Cloning efficiency was $1 \times 10^{6}$ plaque-forming units $/ \mu \mathrm{g}$ of EMBL3. The plates were then screened with the $\mathrm{C} \mu$ probe using the method of Benton and Davis (4). Large scale preparations of phage DNA were made using lysis cultures. Restriction mapping and subcloning were performed using standard techniques (5). Sequence analysis was performed on single stranded DNA from M13 subclones using Sequenase (United States Biochemical Co., Cleveland, $\mathrm{OH}$ ) according to the manufacturer's instructions.

The probes used for hybridization were those described by Rabbitts et al. for $\mathrm{JH}$ and $\mathrm{C} \mu(6)$.

\section{Results}

Rationale for this study. The disadvantage of molecular techniques of being able to study only a relatively small region using standard Southern blotting techniques, is offset somewhat by the observation that when the IgH gene participates in translocations certain portions of the gene are involved much more frequently in the abnormal rearrangements than others. One such region frequently involved in abnormal rearrangements is the intron between $\mathrm{C} \mu$ and $\mathrm{JH}$ which contains the IgH enhancer and the $\mathrm{C} \mu$-associated switch region. This region is involved particularly frequently in the $t(8 ; 14)$ in Burkitt's lymphoma. The $\mathrm{JH}-\mathrm{C} \mu$ region of the IgH gene extends over $\sim 18$ $\mathrm{kb}$ and is now fully mapped. In the germline configuration $\mathrm{C} \mu$ is the nearest constant region segment to $\mathrm{JH}$ and lies $7 \mathrm{~kb} \mathrm{3}$ to the sixth $\mathrm{J}$ segment. $\mathrm{JH}$ and $\mathrm{C} \mu$ are separated by an intron which contains both an enhancer region (7) and a switch region (8). During class switching, which takes place in the secondary immune response, a break occurs, usually within the $S \mu$ region, and a different IgH constant region gene segment replaces $\mathrm{C} \mu$ which is deleted (9).

From inspection of the restriction map of this region in its germline configuration (Fig. 1) it is seen that $\mathrm{JH}$ and $\mathrm{C} \mu$ both lie within the same 18-kb BamHI fragment. IgH gene rearrangement (involving D-J and later V-DJ joining) will alter the position of the $5^{\prime}$ BamHI site and thus the size of the BamHI fragment containing $\mathrm{JH}$ and $\mathrm{C} \mu$. However, the $3^{\prime}$ BamHI site is not affected. Therefore, before class switch one or two bands of nongermline size will be detected using the $\mathrm{JH}$ probe. The same fragments will also be detected on a Southern blot in a BamHI digest using a $\mathrm{JH}$ or a $\mathrm{C} \mu$ probe. After class switch there will be no signal with $\mathrm{C} \mu$. If, however, an anomalous break has taken place between $\mathrm{JH}$ and $\mathrm{C} \mu$, then the respective probes will detect different BamHI fragments.

Abnormal $\mathrm{JH}-\mathrm{C \mu}$ breaks are found. We have studied patients with a variety of lymphoproliferative disorders (Table I). In all but one (a case of acute lymphoblastic leukemia) the leukemic cells had immunoglobulin on their surface (SIg+) indicating that they were relatively "mature" B cells. Deletion of one of the two $\mathrm{C} \mu$ alleles was seen in 48 of the 236 alleles tested (20\%) indicating that a class switch event had taken place in these cases.

In seven cases, however, the sizes of rearranged BamHI fragments containing $\mathrm{JH}$ and $\mathrm{C} \mu$ were clearly different (Table I and Fig. 1), indicating a translocation or some other anomalous event in the $\mathrm{JH}-\mathrm{C} \mu$ region.

Characterization of anomalous breaks. From these seven cases, two (O17 and K11) were selected for detailed analysis. Phage genomic libraries were constructed and plated. Plaques hybridizing to $\mathrm{C} \mu$ were purified and large scale preparation of recombinants made. Analysis of the recombinant clones confirmed that they behaved in the same way as the fragments detected by Southern blotting of genomic samples, i.e., they contained fragments of the appropriate size that hybridized with $\mathrm{C} \mu$ but not JH probes (Fig. 2). By restriction mapping the point at which the clone diverged from the germline map of the region could be determined. In both cases this was found to be within the switch $\mu$ region (Figs. 3 and 4). The DNA which was foreign to the $\mu$ region of the map could therefore be isolated. Single copy probes were obtained from these regions and their chromosomal origin determined by hybridization against DNA from a panel of rodent-human cell hybrids (gift from $\mathbf{N}$. Spurr, Imperial Cancer Research Fund). In both cases we found that the DNA originated from chromosome 14. This is

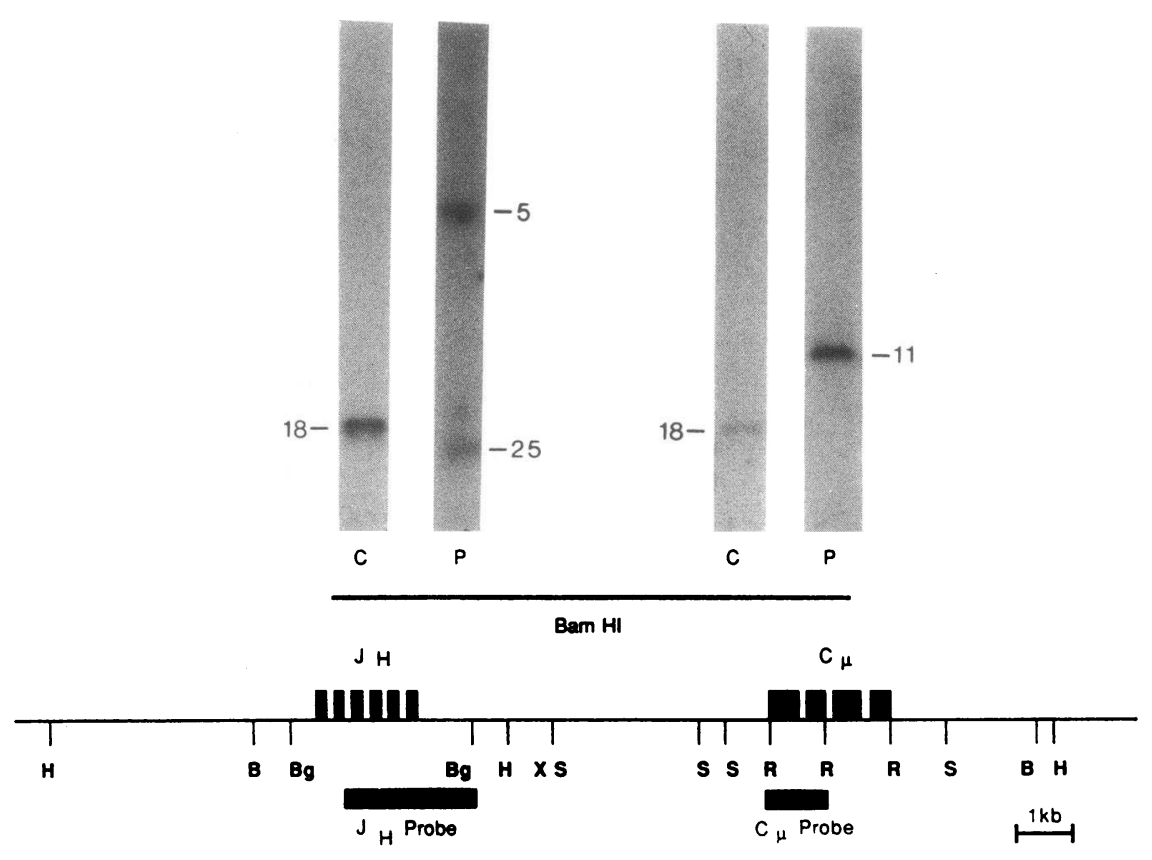

Figure 1. Abnormal separation of $\mathrm{JH}$ and $\mathrm{C} \mu$. At the bottom is shown the restriction map of the $\mathrm{JH}-\mathrm{C} \mu$ region of the human IgH gene. The exons of $\mathrm{JH}$ and $\mathrm{C} \mu$ are shown in black and the probes used in the analysis are shown below. Southern blot analysis of the patient DNA $(P)$ using BamHI and the $\mathrm{JH}$ probe shown above reveals two nongermline fragments consistent with rearrangement of both alleles. Using the $\mathrm{C} \mu$ probe, however, only a single fragment of $11 \mathrm{~kb}$ is detected which matches neither of the $\mathrm{JH}$ fragments. It is concluded that a break has occurred between $\mathrm{JH}$ and $\mathrm{C} \mu$. This was subsequently confirmed (see text). Restriction enzyme sites are shown thus: $R$, EcoRI; $B$, BamHI; $S$, SstI; $H$, HindIII; $B g$, BglII; $X$, XbaI. 
Table I. Cases Analyzed by Diagnostic Category

\begin{tabular}{lrrrr}
\hline & & \multicolumn{2}{c}{ Switch events } & \\
\cline { 3 - 5 } \multicolumn{1}{c}{ Diagnosis } & No. & No. & $\begin{array}{c}\text { Percentage } \\
\text { of alleles }\end{array}$ & $\begin{array}{c}\text { JH-C } \mu \\
\text { breaks }\end{array}$ \\
\hline CLL and CLL/PL & 68 & 16 & $(11.7)$ & 3 \\
PLL & 14 & 10 & $(35.7)$ & 2 \\
HCL & 14 & 16 & $(57.1)$ & 2 \\
WM/Cryo & 3 & 2 & $(33)$ & - \\
NHL & 11 & 2 & $(9.1)$ & - \\
SLVL & 3 & 2 & $(33)$ & - \\
T cell & 4 & 0 & $(0)$ & - \\
cALL & 1 & 0 & $(0)$ & - \\
Total & 118 & 48 & $(20)$ & 7 \\
& & & & \\
\hline
\end{tabular}

CLL and CLL/PL, chronic lymphocytic leukemia and chronic lymphocytic leukemia with prolymphocytes; PLL, prolymphocytic leukemia; HCL, hairy cell leukemia; WM/Cryo, Waldenström's macroglobulinemia/cryoglobulinemia; NHL, non-Hodgkin's lymphoma; SLVL, splenic lymphoma with villous lymphocytes; T cell, cases of T cell phenotype; cALL, common acute lymphoblastic leukemia. The number of switch events was deduced from the number of nongermline $\mathrm{JH}$-containing BamHI fragments that did not contain $\mathrm{C} \mu$ also. This number is also shown as a percentage of the number of alleles analyzed. The number of $\mathrm{JH}-\mathrm{C} \mu$ breaks indicates the number of cases identified in which a nongermline $\mathrm{C} \mu$-containing BamHI fragment did not contain $\mathrm{JH}$ also.

the same chromosome as the IgH locus and the abnormality was therefore most likely to represent an intrachromosomal event rather than a translocation.

The foreign DNA was subcloned in M13 and portions sequenced. Sequence from $\mathrm{O} 17$ had an apparent open reading frame and was therefore compared with the EMBL data base. Surprisingly, it showed an almost complete identity with Cgamma 3, one of the other IgH constant region segments. It was also clear that the Cgamma region in our phage clone was in opposite transcriptional orientation to $\mathrm{C} \mu$. (In the germline Cgamma 3 lies $\sim 60 \mathrm{~kb}$ downstream [3'] of $\mathrm{C} \mu$ and is in the same transcriptional orientation). This unusual configuration immediately suggests that an inversion had occurred in the $\mathrm{IgH}$ gene between $\mathrm{C} \mu$ and Cgamma 3. The juxtaposition of $\mathrm{C} \mu$ and Cgamma3 represents one end of this inversion (Fig. 5). Sequences from either side of the break contained switch sequences in opposite orientation supporting this interpretation.

To clarify the origin of this rearrangement we needed to identify the other end of the inversion. A genomic germline cosmid clone (Ig6) containing the Cgamma 3 region was used for this purpose (10). From this cosmid we isolated a unique sequence probe $3^{\prime}$ from the breakpoint in the region adjacent to Cgamma 3. On a Southern blot this probe lighted the same fragment as $\mathrm{JH}$, thus confirming the other end of the inversion as predicted.

The origin of the foreign DNA in the K11 clone was also facilitated by the use of this clone. A single copy probe was isolated from the $\mathrm{K} 11$ clone which hybridized to the Ig6 clone and thus the position of the second break could be identified (Fig. 4). It was found to lie downstream of Cgamma 3 and within the switch region of Cgamma 1. Although no coding sequences were found the switch sequences on either side of the break were in opposite orientation, suggesting that an inversion

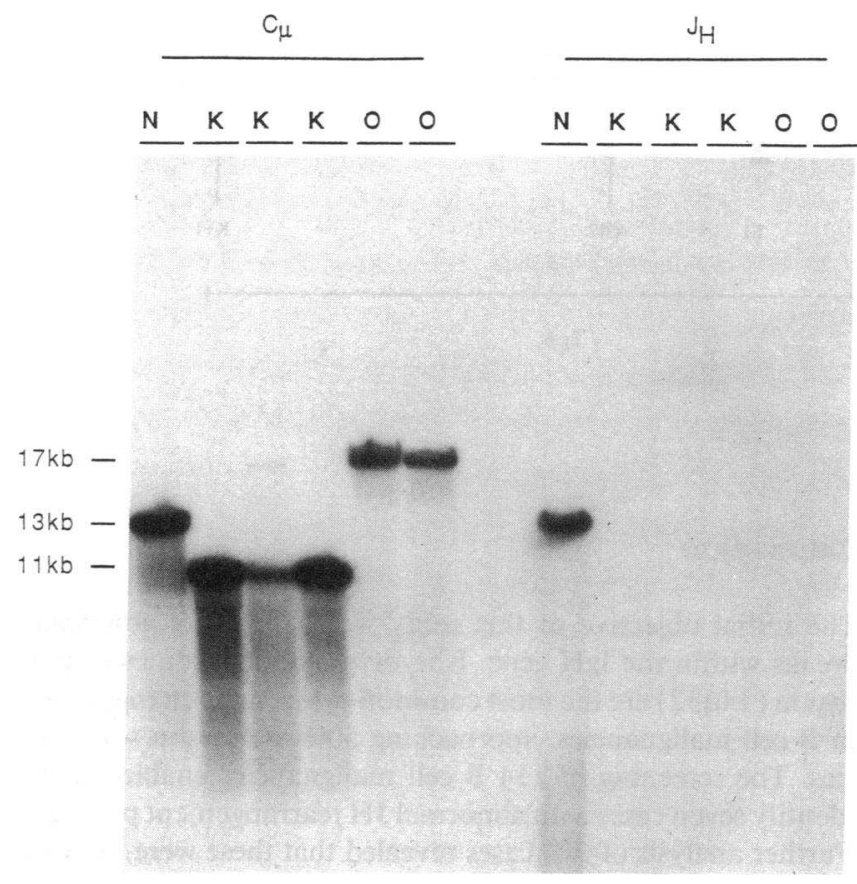

Figure 2. The analysis of the abnormal clones. Duplicate filters made from BamHI digests of the phage clones were hybridized with $\mathrm{JH}$ and $\mathrm{C} \mu$. $O$ and $K$ are clones from the cases described in the text. $N$ is a clone containing $\mathrm{JH}$ and $\mathrm{C} \mu$ in their germline relationship, i.e., on the same BamHI fragment ( $\mathrm{JH}$ rearrangement has taken place so the fragment is not of germ line size). BamHI releases the cloned fragment from the phage vector. The normal clone $\mathrm{N}$ hybridizes with both $\mathrm{JH}$ and $\mathrm{C} \mu$. The $\mathrm{O}$ and $\mathrm{K}$ clones contain fragments of 17 and $11 \mathrm{~kb}$, respectively, which hybridize to $\mathrm{C} \mu$ but not $\mathrm{JH}$, thus confirming their identity with the fragments identified by Southern blot analysis of the genomic DNA. One of the $\mathrm{K}$ clones has become contaminated with some of $\mathrm{O} 17$.

had again taken place. It therefore mimics the first example very closely. Although in this case we have not identified the reciprocal end, it seems certain that the underlying phenomenon is the same.

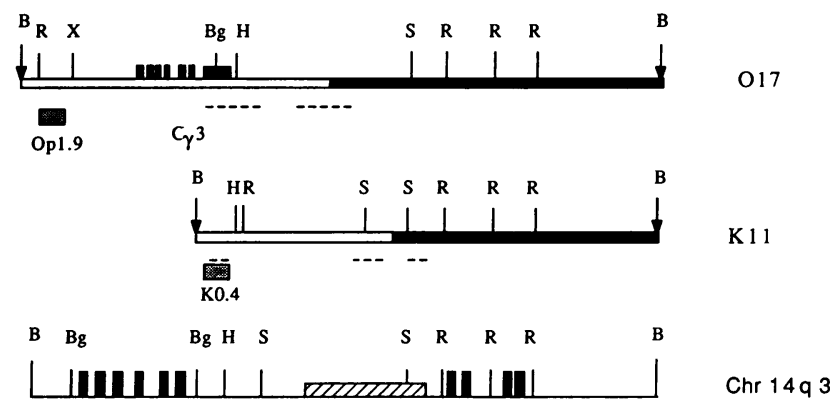

JH

$C_{\mu}$

Figure 3. Restriction maps of the $\mathrm{O} 17$ and $\mathrm{K} 11$ clones. The germline map is shown for comparison. The foreign DNA is shown as unshaded segments. The switch region is shown by the hatched box between $\mathrm{JH}$ and $\mathrm{C}_{\mu}$ in the germline. It can be seen that in both cases the break has occurred within this switch region. The probes isolated for use against cell hybrids (Op1.9 and $\mathrm{KO} .4)$ are shown as stippled boxes. The $\mathrm{C} \gamma 3$ exons in $\mathrm{O} 17$ are shown in black and the regions sequenced denoted by dotted lines. The $\mathrm{JH}$ and $\mathrm{C} \mu$ exons are also shown in black. 


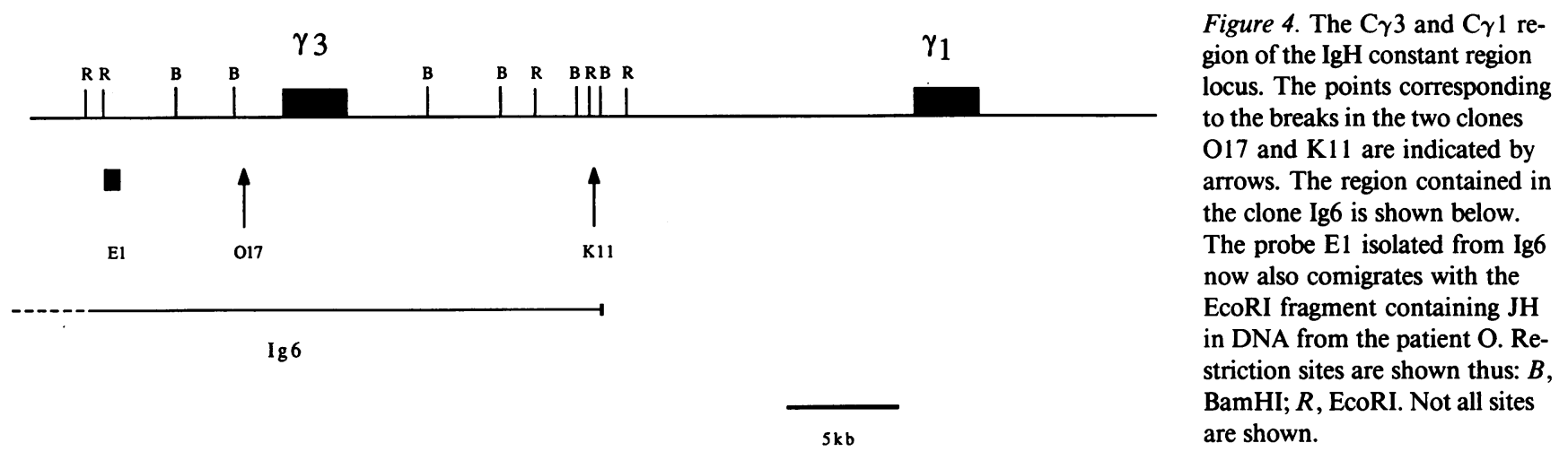

\section{Discussion}

The initial objective of this study was to identify abnormal breaks within the IgH gene. Karyotypic abnormalities of this region (14q32) are the most common cytogenetic changes seen in B cell malignancies, approaching $50 \%$ of cases in some series. The screening of $114 \mathrm{~B}$ cell malignancies enabled us to identify seven cases with abnormal JH rearrangement patterns. Further analysis of two cases revealed that these were not due to translocations but to intrachromosomal inversions involving the IgH switch regions. It is possible that the same is true of the remaining five cases.

What is the significance of these findings in relation to the normal process of class switching? In the germ line $\mathrm{C} \mu$, the $\mathrm{CH}$ segment closest to $\mathrm{JH}$ lies at a distance of $7 \mathrm{~kb}$ downstream to $\mathrm{JH}$, and IgM is the first Ig class to be produced in B cell development. The remainder of the IgH constant regions segments lie downstream of $\mathrm{C} \mu$ in the same transcriptional orientation.

Models of class switch thus far explored fall into two categories.

(a) Without changes at the DNA level. Perlmutter and Gilbert (11) showed that changes in Ig class expression can occur while the $\mathrm{CH}$ segments remain in germline configuration. Their additional finding of long transcripts containing more than one $\mathrm{CH}$ region suggested that this occurred via differential splicing. However, these cells constitute only a small percent- age of splenic lymphocytes. More recently Shimizu et al. (12) have suggested that class switching in transgenic mice can arise through transsplicing of the transgene mRNA to an otherwise sterile transcript of the endogenous germline Cgamma gene. The trans-mRNA in these cases therefore contained only one $\mathrm{CH}$ segment.

(b) Associated with DNA deletions. Normally in mature B cells, such as plasma cells, which have undergone class switching, the complete $\mathrm{VH}$ gene is directly linked to the relevant $\mathrm{CH}$ segment (13) and the intervening $\mathrm{CH}$ genes have been deleted. The IgH constant region segments do not have the specific heptamer-nonamer sequences that appear to guide V-D-J joining. Instead they have in their 5' flanking regions long tandem repeats of simple motifs (GGGCTC and GAGCT). These are believed to mediate the class switch and are therefore referred to as switch sequences.

Several different models have been proposed to explain the precise way in which one $\mathrm{CH}$ region is replaced by another.

(a) Early studies of allotypes associated with a particular idiotype showed that class switch normally takes place within a single chromosome (or between sister chromatids). However, in mice carrying a $\mu$-heavy chain transgene it has been shown that class switch could take place even when the transgene was unlinked to the IgH locus (14). These workers concluded that, at least in this artificial system, class switching could occur between different chromosomes and thus presumably between

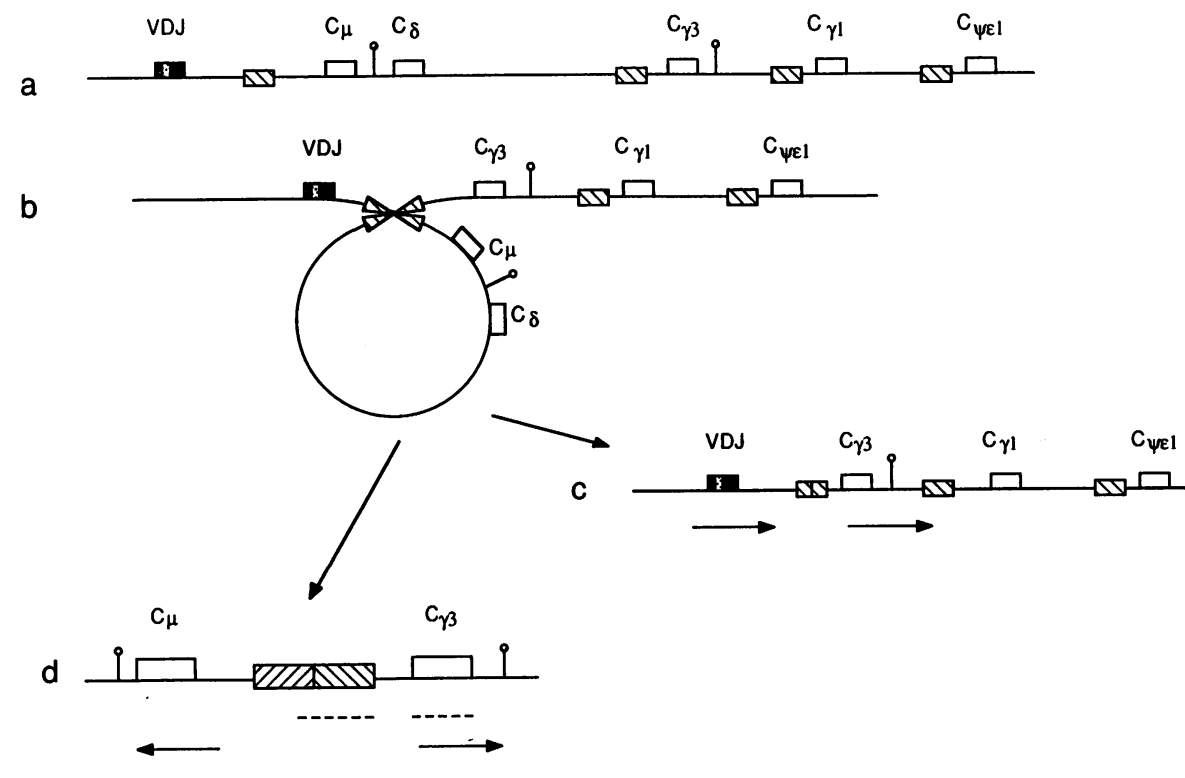

Figure 5. Diagrammatic representation of how both the normal $(c)$ and abnormal (d) switch products are alternative products of a common loop-out intermediate (b). The germline configuration of the $\mathbf{C H}$ locus $(a)$ is shown above. The BamHI sites $\left({ }_{i}\right)$ are shown for reference. The arrows denote the direction of transcription and the hatched boxes the switch regions adjacent to each $\mathrm{CH}$ segment. The dotted lines indicate the segments that were sequenced. 
chromatids, although transsplicing of mRNA remained an alternative explanation.

(b) The sister chromatid exchange (sce) model (15) was proposed to explain the presence of a short $\mathrm{S} \alpha$ sequence between the $S \mu$ and Sgamma 1 sequences upstream from the expressed Cgamma 1 gene in MC101 myeloma cells. This $\mathbf{S} \alpha$ sequence would be absent according to the loop-out model (see below). It may also explain the tandem duplication of gamma 2a genes in the MPC11 cell line (16). However, Wabl et al., in an analysis of 103 subclones of the pre-B cell line 18-81 that can be induced to undergo class switching in vitro from $\mu$ to gamma $2 \mathrm{~b}$ Ig production, found that none contained three copies of $\mathrm{C} \mu$ as predicted by the sce model (17). Thus the relevance of these events to normal class switching is not clear.

(c) The loop-out model proposes that two switch regions on one chromosome are aligned during class switch and the intervening DNA thus forms a loop. After breaking and joining the loop is excised and the new $\mathrm{CH}$ is joined to $\mathrm{S} \mu$ via its own switch region (Fig. 5). The excised DNA, which lacks a centromere, would then be lost. We have isolated from human B cells a structure that could only arise through an event bringing together two $\mathrm{CH}$ regions from the same chromosome. This is exactly in agreement with the loop-out model proven in the mouse when Jack et al. (18) reported the finding of an inversion, similar to the one described here, in the mouse pre-B cell line 18-81. As shown in Fig. 5, this structure is intermediate between both the normal switch product and the abnormal inverted configuration found in the clone described here. von Schwedler et al. (19) subsequently isolated from mouse splenocytes the circular DNA molecules that are the predicted excision products of the loop-out deletion process, and similar findings have subsequently been reported by two other groups $(20$, $21)$. Because we have isolated this rearranged structure from leukemic cells, one might question whether our inference with respect to the class switch is applicable to normal B cells. Obviously we cannot answer this question categorically. Nonetheless the clonal nature of the rearrangement indicates that it took place before the leukemic transformation. Therefore we see no reason to surmise that the cell was in any way abnormal at the time of class switching. On the other hand, the mouse data referred to above were obtained either in a cell line or after stimulation with interleukin 4 or lipopolysaccharide.

Although we have fully elucidated the structure of the anomalous rearrangements in only two of out of seven cases, it is possible that the other five are similar. In this respect we note that only three instances of $\mathrm{JH}-\mathrm{C} \mu$ separation were found in 68 cases of chronic lymphocytic leukemia while four were found in 28 cases of leukemias with a more mature cell phenotype. We presume this is related to the higher proportion of class switch events in the latter groups ( Table I). In our entire series we found seven anomalous rearrangements out of a total of 48 switch events (i.e., $\sim 15 \%$ ). If this is representative of normal $B$ cell development then class switching is a relatively errorprone mechanism.

There are numerous differences between the murine and human IgH genes and therefore in principle extrapolation of results from one species to another must always be performed with caution. The inversion events reported here suggest that the loop-out deletion mechanism is the basis of class switch also in human B lymphocytes. Whereas in the mouse system the process was demonstrated in vitro in a cell line competent for class switching in the human case we have taken advantage of the clonal expansion of a neoplastic cell in which the switch had misfired on one chromosome. This illustrates once again how the analysis of a pathological clone can shed light on a physiological process.

\section{Acknowledgments}

We are grateful to Professor D. Catovsky for allowing us to study cases from his laboratory, T. H. Rabbits for the IgG clone, and L. Foroni for her advice and encouragement.

M. A. Laffan was supported by a Medical Research Council training fellowship.

\section{References}

1. Bartram, C. R., E. Kleihauer, A. de Klein, G. Grosveld, J. R. Teyssier, N. Heisterkamp, and J. Groffen. 1985. C-abl and bcr are rearranged in a $\mathrm{Ph}^{\prime}$ negative CML patient. EMBO (Eur. Mol. Biol. Organ.) J. 3:683-686.

2. Foroni, F., D. Catovsky, and L. Luzzatto. 1987. Immunoglobulin gene rearrangements in hairy cell leukemia and other chronic B cell lymphoproliferative disorders. Leukemia (Baltimore). 4:389-392.

3. Kaiser, K., and N. E. Murray. 1985. The use of phage lambda replacement vectors in the construction of representative genomic DNA libraries. In DNA Cloning. Vol. 1. A Practical Approach. D. M. Glover, editor. IRL Press Ltd., Oxford. 1-47.

4. Benton, W. D., and R. W. Davies. 1977. Screening $\lambda$ gt recombinant clones by hybridization to single plaques in situ. Science (Wash. DC). 196:180-186.

5. Maniatis, T., E. F. Fritsch, and J. Sambrook. 1982. Molecular Cloning: A Laboratory Manual. Cold Spring Harbor Laboratory Press, Cold Spring Harbor, NY.

6. Foroni, F., D. Catovsky, T. H. Rabbitts, and L. Luzzatto. 1984. DNA rearrangements of immunoglobulin genes correlate with phenotypic markers in B-cell malignancies. Mol. Biol. \& Med. 2:63-69.

7. Gillies, S. D., S. L. Morrison, V. T. Oi, and S. Tonegawa. 1983. A tissue specific transcription enhancer element is located in the major intron of a rearranged immunoglobulin heavy chain gene. Cell. 33:717-728.

8. Rabbitts, T. H., A. Forster, and C. P. Milstein. 1981. Human immunoglobulin heavy chain genes: evolutionary comparison of $\mathrm{C} \mu, \mathrm{C} \delta$ and $\mathrm{C}_{\gamma}$ genes and associated sequences. Nucleic Acids Res. 9:4509-4524.

9. Radbruch, A., C. Burger, S. Klein, and W. Muller. 1986. Control of immunoglobulin class switch recombination. Immunol. Rev. 89:69-83.

10. Flanagan, J. G., and T. H. Rabbitts. 1982. Arrangement of human immunoglobulin heavy chain constant region genes implies evolutionary duplication of a segment containing gamma, epsilon and alpha genes. Nature (Lond.). 300:709713 .

11. Perlmutter, A. P., and W. Gilbert. 1984. Antibodies of the secondary response can be expressed without switch recombination in normal mouse $B$ cells. Proc. Natl. Acad. Sci. USA. 81:7189-7193.

12. Shimizu, A., M. C. Nussenzweig, T.-R. Mizuta, P. Leder, and T. Honjo. 1989. Immunoglobulin double isotype expression by trans-mRNA in a human immunoglobulin transgenic mouse. Proc. Natl. Acad. Sci. USA. 86:8020-8023.

13. Davis, M. M., K. Calame, P. W. Early, D. L. Livant, R. Joho, I. L. Weismann, and L. Hood. 1980. An immunoglobulin heavy chain gene is formed by at least two different recombinational events. Nature (Lond.). 283:733-739.

14. Durdik, J., R. M. Gerstein, S. Rath, P. F. Robbins, A. Nisonoff, and E Selsing. 1989. Isotype switching by a microinjected $\mathrm{m}$ immunoglobulin heavy chain gene in transgenic mice. Proc. Natl. Acad. Sci. USA. 86:2346-2350.

15. Obata, M., T. Kataoka, S. Nakai, H. Yamagishi, N. Takahashi, Y. Yamawaki-Kataoka, T. Nikaido, A. Shimizu, and T. Honjo. 1981. Structure of a rearranged gamma 1 chain gene and its implication for immunoglobulin classswitch mechanism. Proc. Natl. Acad. Sci. USA. 78:2437-2441.

16. Tilley, S. A., and B. K. Birshtein. 1985. Unequal sister chromatid exchange. J. Exp. Med. 162:675-694.

17. Wabl, M., J. Meyer, G. Beck-Engeser, M. Tenkhoff, and P. D. Burrows. 1985. Critical test of a sister chromatid exchange model for the immunoglobulin heavy-chain class switch. Nature (Lond.). 313:687-689.

18. Jack, H.-M., M. McDowell, C. M. Steinberg, and M. Wabl. 1988. Looping out and deletion mechanism for the immunoglobulin heavy-chain class switch. Proc. Natl. Acad. Sci. USA. 85:1581-1585.

19. von Schwedler, U., H.-M. Jack, and M. Wabl. 1990. Circular DNA is a product of the immunoglobulin class switch rearrangement. Nature (Lond.). 345:452-455.

20. Iwasato, T., A. Shimizu, T. Honjo, and H. Yamagishi. 1990. Circular DNA is excised by immunoglobulin class switch recombination. Cell. 62:143149.

21. Matsuoka, M., K. Yoshida, T. Maeda, S. Usuda, and H. Sakano. 1990. Switch circular DNA formed in cytokine treated mouse splenocytes: evidence for intramolecular DNA deletion in immunoglobulin class switching. Cell. 62:135142. 